\title{
Skin and kin
}

\author{
Celia Moss
}

J R Soc Med 2005;98:200-202

The skin, as an organ, is often taken for granted, seen as cosmetic coverage for the more important technology on the inside. Its vital metabolic, immunological, homeostatic and barrier functions are easily overlooked-perhaps because, as an organ, it so rarely fails. The skin's robustness is particularly remarkable since, unlike the protected internal organs, its existence and integrity are constantly threatened by physical damage, wear and abuse. The particular property of skin to stay in place, stuck firmly on the body, is complex, underestimated, and devastating when faulty. Dear reader in 2055, let me tell you a story of genetic disorder and our hopes for a better medical future.

When Saira was born in Birmingham in August 1987, the second child of first-cousin Pakistani immigrants, the midwife noticed some raw areas on her skin. Over the next few days blisters appeared in several places - where the umbilical clip had rubbed, under the edges of her nappy, where adhesive tape had been removed, and even inside her mouth from the teat of a bottle. It was clear that the adhesion of her skin and mucosal surfaces was far too easily disrupted, by friction, traction, suction and heat, and by pressure on small blisters which rapidly spread along a plane of cleavage, reaching several centimetres in diameter.

The clinical diagnosis of epidermolysis bullosa (EB), a genetic blistering disorder, was confirmed by skin biopsy. Light microscopy showed a split at the junction between epidermis and dermis. Electronmicroscopy confirmed that this was not the superficial (simplex) type of EB, nor the deep scarring (dystrophic) type, but the potentially lethal junctional type. Saira's family was told that her condition was incurable and that she would probably die from infection, laryngeal blistering, malnutrition, or other complications, before her first birthday. But she didn't. It was not until the mid-1990s that it became possible to distinguish between lethal Herlitz junctional EB, caused by mutations in the laminin 5 genes, and 'non-Herlitz' junctional EB usually caused by mutations in collagen XVII, the bullous pemphigoid antigen (BPAG2).

So Saira began a life sentence of pain and disfigurement, a diet of sloppy food and supplements, a daily regimen of

Celia Moss, DM FRCP, is a consultant dermatologist at Birmingham Children's Hospital. She has a major interest in genetic dermatology.

Children's Hospital, Steelhouse Lane, Birmingham B4 6NH, UK

E-mail: celia.moss@bch.nhs.uk needles, blisters and dressings, punctuated by crises due to infection, oesophageal obstruction and anaemia. But Saira confounded everyone, not only by her refusal to die but also by her spirited determination to live life to the full. As a child she rode a tricycle despite terrible friction blisters. She wears stylish clothes on top of her extensive dressings, switching between jeans and salwar kameez. She enjoys parties and family celebrations, loves shopping, jewellery and pop music, and occasionally misbehaves just like any other 17-year-old. She is intelligent, funny, lovable, articulate and insightful. She is usually, but not always, positive and cheerful. Sometimes her situation is almost too much to bear.

The exposed location which makes skin so vulnerable also makes it uniquely accessible to investigation. Despite its rarity-junctional EB occurs in about 20 per million births - the pathogenesis of EB was already well established at a time when major genetic disorders of the brain and heart remained obscure. The three main types of EB were delineated clinically and histologically by the 1960 s (Table 1). Electronmicroscopy in the 1970s revealed abnormal epidermal keratin filaments in EB simplex, disordered dermal anchoring fibrils in dystrophic EB, and defective hemidesmosomes in junctional EB. Antigens identified by immunohistochemistry in the 1980s led in the 1990s to discovery of the major EB genes, encoding keratins 5 and 14 in EB simplex, collagen VII in dystrophic EB, and laminin 5 in Herlitz junctional EB. Towards the end of the millennium, as the complex structure of desmosomes and hemidesmosomes was unravelled, genes responsible for the rare subtypes were found - $\alpha 6 \beta 4$ integrin for EB with pyloric atresia; plectin for EB with muscular dystrophy; plakophilin for EB with ectodermal dysplasia. In 1995 mutations in the $180 \mathrm{kD}$ bullous pemphigoid antigen BPAG2, later renamed collagen XVII, were reported in some patients with non-syndromic nonHerlitz(non-lethal) junctional EB of the type suffered by Saira. Non-Herlitz junctional EB may also result from less severe mutations in laminin 5 .

When Saira was 4 years old her mother conceived again. She acknowledged the 1 in 4 risk of having another affected child with this autosomal recessive disorder, and chose to avoid it. At that time the only method of antenatal diagnosis was ultrastructural and immunohistochemical examination of a fetal skin biopsy sampled in utero, which could not be 
Table 1 Types of epidermolysis bullosa (EB) and their characteristics

\begin{tabular}{|c|c|c|c|c|c|}
\hline Light microscopy & \multicolumn{2}{|c|}{ Electronmicroscopy } & Protein/antigen & Gene & Type of EB \\
\hline \multirow[t]{4}{*}{ Epidermis } & \multirow{2}{*}{\multicolumn{2}{|c|}{ Keratin filaments }} & \multirow{2}{*}{$\begin{array}{l}\text { Keratin } 5 \\
\text { Keratin } 14\end{array}$} & \multirow{2}{*}{$\begin{array}{l}\text { KRT5 } \\
\text { KRT14 }\end{array}$} & EB simplex (Dowling-Meara) \\
\hline & & & & & EB simplex (Weber-Cockayne) \\
\hline & Desmosome & Attachment plaque & Plakophilin & $P K P 1$ & EB with ectodermal dysplasia \\
\hline & \multirow{3}{*}{$\begin{array}{l}\text { Hemidesmosome } \\
\text { lamina lucida }\end{array}$} & & Plectin & PLEC1 & EB with muscular dystrophy \\
\hline \multirow{3}{*}{$\begin{array}{l}\text { Basement } \\
\text { membrane zone }\end{array}$} & & Sub-basal dense plate, & Collagen XVII & BPAG2 & Non-Herlitz junctional EB \\
\hline & & & $\alpha 6 \beta 4$ integrin & $\begin{array}{l}\text { ITGA6 } \\
\text { ITGB4 }\end{array}$ & Junctional EB with pyloric atresia \\
\hline & \multicolumn{2}{|l|}{ Lamina densa } & Laminin 5 & $\begin{array}{l}\text { LAMA3 } \\
\text { LAMB3 } \\
\text { LAMC2 }\end{array}$ & $\begin{array}{l}\text { Herlitz junctional EB } \\
\text { Rarely, non-Herlitz junctional EB }\end{array}$ \\
\hline Dermis & \multicolumn{2}{|l|}{ Anchoring fibrils } & Collagen VII & COL7A1 & Dystrophic EB \\
\hline
\end{tabular}

done until the skin was adequately developed at around 16 weeks' gestation. The fetus showed the same electronmicroscopic abnormality as Saira's skin and the pregnancy was terminated. Later Saira's aunt followed the same path, having lost her first infant son to septicaemia secondary to EB. In this second pregnancy the fetal skin biopsy was normal and a healthy baby was born.

Saira does not have a mutation in any of the laminin 5 (Herlitz) genes. She probably has a BPAG2 mutation, which has not been identified yet in her DNA but should be soon. The timing is critical for her older brother, who may or may not be a carrier, would like to marry a cousin in Pakistan, and is keen to know the risk. Future pregnancies can then be investigated by analysis of fetal DNA extracted from a chorionic villus sample. This has the advantage over fetal skin biopsy that it can be done earlier, allowing termination within the first trimester. Chorionic villus diagnosis is already available for most families with Herlitz junctional EB and severe dystrophic EB. For families who prefer to avoid termination of pregnancy altogether, preimplantation DNA-based diagnosis is preferable and possible but not yet available. Meanwhile Saira, the survivor, struggles to come to terms with the death of her affected baby cousin and the implications of antenatal choice.

EB is an expensive disorder. Diagnostic tests demand advanced technology; skin care requires a vast quantity of creams and dressings; medical treatment is specialized and multidisciplinary; the support of sufferers through education and employment is costly. For 27 years the Dystrophic Epidermolysis Bullosa Research Association (DEBRA), a charity set up by parents, has provided for the needs of people with EB, funding nursing care, educational resources, family support, and essential research. However, in the past three years EB funding has moved into the public sector. Recognition of the importance and cost of highly specialized care for rare diseases led to the development of the National Specialist Commissioning Advisory Group (NSCAG). In 2002 NSCAG designated and funded four centres for the management of $\mathrm{EB}$, in London and Birmingham - two for adults and two for children. Maintenance of the EB service through changing political agendas will remain a challenge. We still rely heavily on the DEBRA charity.

EB has also cost this family dear. Saira's father left them, and her mother has struggled not only with Saira's EB, single parenthood, and her own ill-health, but also with ostracism. The family endured a period of homelessness, living in a hostel while waiting to be rehoused after repeated harassment. Saira has even been asked to go home from parties because her appearance upset other guests. She knows all about bullying, from outside and inside her own community. The 11 September 2001 terrorist attacks on the Twin Towers of the World Trade Center in New York drew unwanted attention to the Pakistani Muslims who comprise $20 \%$ of the Birmingham population. Mainly from rural Mirpur in Kashmir, they have built mosques, opened schools, and maintained traditional cultural practices and family structures to a remarkable degree.

The future for Saira is uncertain. Her condition, although not directly life-threatening, carries a high morbidity. To keep her comfortable is a major daily challenge which her mother will not always be able to share. Likewise her nutrition: Saira's requirements are high because of constant loss of blood and nutrients from the skin, and her intake is compromised by oral blistering, defective teeth, and oesophageal narrowing from mucosal damage. Every day Saira requires nine medications and supplements, eight creams and six types of dressing. Added to all this is the spectre of skin cancer. $80 \%$ of people with 
severe EB surviving to adulthood eventually succumb to metastatic squamous cell carcinoma originating in chronic wounds. Saira herself, now attending sixth form college, plans to develop her already impressive computer skills and set up a business. Knowing her, she will probably succeed.

There is considerable research internationally in EB, with a major laboratory at St Thomas' Hospital in London. Now that most of the genes are known and accurate diagnosis is theoretically possible, the major thrust of research is treatment and prevention of complications. There are three main foci-wound healing, skin cancer, and gene therapy. The first two are related: skin cancers tend to develop in chronic unhealed wounds and scars. The last, the potential cure, is what patients hope and pray for. Gene therapy is in its infancy and only available for a handful of conditions at research institutions. But considerable background work has been done towards gene therapy for EB. It is already possible to insert the normal gene into EB keratinocytes cultured in the laboratory. Both dystrophic and junctional EB cells can be rendered normal in all respects in vitro. Corrected Herlitz junctional EB cells have been grafted successfully to immunodeficient mice. But before corrected cells can be grafted to patients, there are considerable obstacles to be surmounted. Hospitals that attempt the treatment must comply with exacting ethical and safety regulations. Other sorts of gene therapy have met with setbacks; for example, trials were suspended in 2003 after two of ten patients with severe combined immunodeficiency developed leukaemia 3 years after gene therapy. Dermatologists and surgeons will also need to work on the best methods for debridement and grafting. But there is good reason to hope that gene therapy for EB will be available within the next 10 years.

Tremendous advances in EB diagnosis and management have taken place during Saira's lifetime. Sadly, most came just too late to meet her family's particular needs - for accurate neonatal diagnosis, early DNA-based antenatal diagnosis and carrier detection. We hope that the most eagerly awaited one, gene therapy, will arrive in time to help Saira herself as well as the next generation.

Acknowledgments I thank Professor Robin Eady, Professor Anthony Ferner and the patient (Saira is a pseudonym) for helpful comments. 